\title{
A global analysis of bird plumage patterns reveals no association between habitat and camouflage
}

\author{
Marius Somveille Corresp., 1, 2 , Kate LA Marshall ${ }^{1}$, Thanh-Lan Gluckman ${ }^{1,3,4}$ \\ 1 Department of Zoology, University of Cambridge, Cambridge, United Kingdom \\ 2 The Edward Grey Institute, Department of Zoology, University of Oxford, Oxford, United Kingdom \\ 3 Department of Animal and Plant Sciences, University of Sheffield, Sheffield, United Kingdom \\ ${ }^{4}$ Center for Interdisciplinary Research in Biology, College de France, Paris, France \\ Corresponding Author: Marius Somveille \\ Email address: marius.somveille@zoo.ox.ac.uk
}

Evidence suggests that animal patterns (motifs) function in camouflage. Irregular mottled patterns can facilitate concealment when stationary in cluttered habitats, whereas regular patterns typically prevent capture during movement in open habitats. Bird plumage patterns have predominantly converged on just four types - mottled (irregular), scales, bars and spots (regular) - and habitat could be driving convergent evolution in avian patterning. Based on sensory ecology, we therefore predict that irregular patterns would be associated with visually noisy closed habitats and that regular patterns would be associated with open habitats. Regular patterns have also been shown to function in communication for sexually competing males to stand-out and attract females, so we predict that male breeding plumage patterns evolved in both open and closed habitats. Here, taking phylogenetic relatedness into account, we investigate ecological selection for bird plumage patterns across the class Aves. We surveyed plumage patterns in $80 \%$ of all avian species worldwide. Of these, 2756 bird species have regular and irregular plumage patterns as well as habitat information. In this subset, we tested whether adult breeding/non-breeding plumages in each sex, and juvenile plumages, were associated with the habitat types found within the species' geographical distributions. We found no evidence for an association between habitat and plumage patterns across the world's birds and little phylogenetic signal. We also found that species with regular and irregular plumage patterns were distributed randomly across the world's eco-regions without being affected by habitat type. These results indicate that at the global spatial and taxonomic scale, habitat does not predict convergent evolution in bird plumage patterns, contrary to the camouflage hypothesis. 
1 Title: A global analysis of bird plumage patterns reveals no association between habitat and

2 camouflage

3 Authors: Marius Somveille ${ }^{1,2}$, Kate Marshall ${ }^{1}$, Thanh-Lan Gluckman ${ }^{1,3,4}$

4

$5{ }^{1}$ Department of Zoology, University of Cambridge, Downing Street, Cambridge, CB2 3EJ, UK.

62 The Edward Grey Institute, Department of Zoology, Tinbergen Building, University of Oxford,

7 South Parks Road, Oxford, OX1 3PS, UK.

$8{ }^{3}$ Department of Animal and Plant Sciences, University of Sheffield, Alfred Denny Building,

9 Western Bank, S10 2TN, UK.

$10{ }^{4}$ Center for Interdisciplinary Research in Biology, College de France, Paris 75005, France.

11 Short running title: Global analysis of bird plumage patterns

12 Corresponding author: Marius Somveille

13 Mailing address: Edward Grey Institute, Department of Zoology, Tinbergen Building, University

14 of Oxford, South Parks Road, Oxford, OX1 3PS, UK

15 Tel: $+44(0) 1865271255$

16 E-mail: marius.somveille@zoo.ox.ac.uk 


\section{Abstract}

Evidence suggests that animal patterns (motifs) function in camouflage. Irregular mottled patterns can facilitate concealment when stationary in cluttered habitats, whereas regular patterns

21 typically prevent capture during movement in open habitats. Bird plumage patterns have

22 predominantly converged on just four types - mottled (irregular), scales, bars and spots (regular)

23 - and habitat could be driving convergent evolution in avian patterning. Based on sensory

24 ecology, we therefore predict that irregular patterns would be associated with visually noisy

25 closed habitats and that regular patterns would be associated with open habitats. Regular patterns

26 have also been shown to function in communication for sexually competing males to stand-out

27 and attract females, so we predict that male breeding plumage patterns evolved in both open and

28 closed habitats. Here, taking phylogenetic relatedness into account, we investigate ecological

29 selection for bird plumage patterns across the class Aves. We surveyed plumage patterns in $80 \%$

30 of all avian species worldwide. Of these, 2756 bird species have regular and irregular plumage

31 patterns as well as habitat information. In this subset, we tested whether adult breeding/non-

32 breeding plumages in each sex, and juvenile plumages, were associated with the habitat types

33 found within the species' geographical distributions. We found no evidence for an association

34 between habitat and plumage patterns across the world's birds and little phylogenetic signal. We

35 also found that species with regular and irregular plumage patterns were distributed randomly

36 across the world's eco-regions without being affected by habitat type. These results indicate that

37 at the global spatial and taxonomic scale, habitat does not predict convergent evolution in bird

38 plumage patterns, contrary to the camouflage hypothesis. 


\section{Introduction}

Selection for optimal camouflage and sexual signals in the different habitats of animals can drive phenotypic variation (e.g. Endler, 1978; Stuart-Fox \& Ord, 2004; Hoekstra et al., 2006; Rosenblum, 2006; Seehausen et al., 2008; reviewed in Stevens, 2013). Animals exhibit a diversity of pigmentation patterns or motifs (i.e., stipples) that are predominantly thought to function in camouflage, such as by generally matching the background or by breaking up (disrupting) the prey outline and creating false edges to prevent detection by predators (Thayer, 1909; Cott, 1940; Pough, 1976; Stevens \& Merilaita, 2009). Under sensory ecology theory, the likelihood of a predator being able to detect its prey depends on how effectively the visual cue is transmitted to the predator's eye, and on how well the predator's specific visual system can detect/recognise its prey against the background on which it is viewed (e.g. Endler, 1992). Past studies have shown that genetic adaptation of camouflage appears to enhance background matching in local environments and increase survival against visual predators (e.g. Hoekstra et al., 2005; Vignieri et al., 2010). Crucially, visual modelling studies have shown that such local adaptation can prevent detection by the actual visual systems of predators, such as hunting birds (e.g. Stuart-Fox et al., 2004; Marshall et al., 2015), thus indicating that camouflage tends to be optimised to local habitats under natural selection.

Across animals, different types of visual patterns made up of different patches of pigmentation to make up an overall pattern or 'motif' have been linked to different functions in camouflage. Specifically, irregular patterns (mottled) tend to function in stationary camouflage while those that regularly repeat a pattern or motif (bars, spots) function in motion camouflage, which are in turn predicted to be more effective in closed and open habitats, respectively 
61 (Marshall and Gluckman, 2015). Birds are the most well described taxonomic group of animal

62 and can be found in all types of habitats on all major landmasses (Gluckman \& Cardoso, 2010;

63 Jetz et al., 2012), making them particularly well suited for investigating sensory ecology

64 hypotheses. Recent studies on bird colouration across a large number of species and at large

65 spatial scale revealed that islands are associated with reduced signal intensity (Doutrelant et al.,

66 2016) and that colour heterogeneity decreases with body size (Galvan et al. 2013), but also

67 showed distinct effects of habitat, life history and sexual selection on the evolution of

68 colouration that lacks patterning (an absence of patterns or uniform colouration), such as bright

69 red carotenoid and dull brown melanins (Dale et al. 2015; Dunn et al. 2015). However, no study

70 has yet explicitly examined the role of habitat and camouflage on avian feather patterns type at

71 the global scale (but see Riegner 2008; Gluckman and Cardoso 2010).

In spite of the spectacular diversity in phenotypes across the class Aves, bird plumage patterns have predominantly converged on just four types: mottled, scales, bars and spots (Fig. 1;

74 Gluckman 2014; Marshall \& Gluckman, 2015; Gluckman \& Mundy 2016). Most studies of

camouflage focus on single or few species (Marshall \& Gluckman 2015) that may not be

representative of broad scale selection pressures. Here, we investigated whether sensory ecology global spatial and taxonomic scale, i.e., with a global spatial extent, using large spatial units, and data on most land bird species.

It is thought that irregular patterns function in the camouflage of stationary animals through background matching and disruptive camouflage, in order to evade detection by predators (Thayer, 1909; Cott, 1940; Endler, 1978; Bradbury \& Vehrencamp, 1998). 
84 cluttered backgrounds containing distractors (e.g. Dimitrova \& Merilaita, 2009). Therefore,

85 irregular patterns should be favoured in visually complex closed environments that provide

86 backgrounds where a prey animal can easily blend in. Irregular mottled patterns are common in

87 avian species, and are more frequently found in females and juveniles in comparison to regular

88 barred plumage patterns (Gluckman \& Cardoso, 2010).

Current evidence suggests that regular patterns, such as bars and spots, typically facilitate camouflage during movement and therefore function as a secondary defence during the escape of prey by exploiting specific features of receiver visual acuity. This type of camouflage would include motion dazzle, whereby highly contrasting patterns prevent predators from estimating the speed and direction of moving prey (e.g. Scott-Samuel et al., 2011; Stevens et al., 2008, 2011; von Helversen et al., 2013; How and Zanker, 2014; Hughes et al., 2014) as well as flicker-fusion camouflage, in which the patterns of a moving animal become blurred to the predator's vision so that it appears to match the background against which it is moving (e.g. Brodie, 1989, 1992, 1993; Lindell \& Forsman, 1996). Given that escape by flight requires space and that motion camouflage is dependent on effective transmission to the predator's eye, regular patterns in birds should be more common in open habitats where patterns are easily visible and escape by flight is unencumbered. Additionally, regular patterns may have a dual function in both camouflage and visual communication with conspecifics (Marshall, 2000; Gluckman \& Cardoso, 2010) and, due to multiple functions, may evolve independently of habitat in adult males (Bradbury and Vehrencamp, 1998; Endler, 1992; Kenward et al., 2004; Leal \& Fleishman, 2004; Seehausen et al., 2008; McLean et al., 2014).

Across the world, habitats differ in their structural composition, e.g. forested habitats are cluttered and visually noisy, while desert habitats are not. The dorsal plumage patterns of birds 
107 are likely to function in camouflage in adults of both sexes, as well as juveniles, whereas a

108 communication function is likely to evolve on the ventral surface of sexually competing males

109 (Stuart-Fox \& Ord, 2004; Gluckman \& Cardoso, 2010; Garcia et al., 2013).

110 In this study, we investigated whether habitat selects for convergent evolution in the

111 plumage patterns of terrestrial birds at the global scale, using the geographical distribution of all

112 known avian species (excluding sea birds). Firstly, we looked for an association between

113 plumage patterns type and habitat type across avian species; and secondly, we investigated

114 whether patterned species were distributed at random across the world. We expected to find a

115 significant association between closed and open habitats with irregular and regular patterns,

116 respectively, in the plumage of adults as well as juveniles. In the sexually selected ventral

117 plumage of breeding males, we expected that plumage pattern evolution would be independent of

118 habitat due to its function in communication. In addition, we expected the distribution of

119 irregularly and regularly patterned species across geographical space to differ from random and 120 be affected by habitat.

\section{Material and Methods}

123

124

125

126

127

\section{Data collection}

We focused on the most prominent aspect of patterning: the four different types of spatial arrangement of pigmentation (Fig. 1). To collect plumage pattern information we referred to field guides covering all major landmasses: North and Central America (Sibley, 2000; van Perlo, 2006), South America and Antarctica (De La Pena \& Rumboll, 1998; Restall et al., 2007), sub- 
128 Saharan Africa and Madagascar (Langrand, 1990; Sinclair \& Ryan, 2003), Europe, North Africa

129 and Central Asia (Heinzel et al., 1995; Grimmett et al., 1999; Arlott, 2007, 2009; Brazil, 2009),

130 East and South-East Asia (MacKinnon \& Phillips, 1993; Coates \& Bishop, 1997; Robson, 2005),

131 and Oceania (Beehler et al.,1986; Pratt et al., 1987; Simpson \& Day, 2004; Robertson \&

132 Heather, 2005). Where multiple subspecies were present, we collected information on the

133 nominate subspecies. Overall, we examined 8006 avian species ( $80 \%$ of class Aves) to

134 categorize their patterning. Juvenile plumages are less frequently drawn in field guides so we

135 were only able to categorise juvenile plumage information in 2603 species (26\% of class Aves).

136 Species that were unpatterned and/or without habitat information were excluded from further

137 statistical analyses, giving an overall sample size of 2756 avian species (34\% of the species

138 considered), providing information for 2593 adult and 2104 juvenile avian species (see the list of

139 species in Appendix S1).

140 We scored the plumage of both sexes as well as juveniles of each species for: an absence

141 of patterns, mottled, scaled, barred and spotted patterns, both on the ventral and dorsal surface,

142 separately (Fig. 1). Irregular mottled patterns were defined as pigmentation that did not have a

143 clearly discernible motif or the putative motif had irregular borders, as frequently found on the

144 dorsum of sparrows (in contrast with the stripes of species from the genus Gavia that have clear

145 and neat boundaries in the stripes on the neck). Regular patterns had a motif with regular borders

146 and were repeated across a patch of patterning (Fig. 1). Some species have multiple patterns on

147 either the ventral or dorsal surface (e.g., the male zebra finch, Taeniopygia guttata, has barred

148 patterns on the breast and spotted flanks): on the ventral surface, 62 and 64 species for males

149 during the non-breeding and breeding seasons respectively, 70 and 72 species for females during

150 the non-breeding and breeding seasons respectively, and 63 species for juveniles; and on the 
151 dorsal surface, 229 and 222 species for males during the non-breeding and breeding seasons

152 respectively, 231 and 233 species for females during the non-breeding and breeding seasons

153 respectively, and 102 species for juveniles. In these types of species, all of the different types of

154 plumage patterns on each surface were scored and each pattern type was analysed separately.

155 Where species exhibited variable patterns between moults, we collected the breeding and non-

156 breeding plumage given that there may be variation in selection pressure on the different types of 157 patterns exhibited. Squares, triangles and stripes also occur within the plumage of birds, but are

158 comparatively rare (e.g. out of these three rare patterns stripes are the most common: 43 species).

159 Stripes are comprised of regular longitudinal lines (unlike bars, which are pigmented transversal

160 to the feathers axis). These rare types of patterns were excluded from the analysis due to low

161 statistical power.

162 We examined all of the combinations of gender/age (male/female/juvenile), season

163 (breeding/non-breeding), and body part (ventral/dorsal), individually. Herein we refer to each as

164 biological combinations.

Species geographical distributions

Global geographical distributions of all avian species were obtained from Birdlife

168

169

170

171

172

International and NatureServe (Birdlife International \& NatureServe 2012) for all species in the plumage dataset and treated as described in Somveille et al. (2013). Briefly, the polygons in the dataset represent the global distribution of species and we included only the polygons for which species presence was coded as extant or probably extant and the species origin was coded as native or reintroduced, and we excluded the polygons corresponding to species in passage (i.e. 
173 during migration). In addition, breeding distributions (defined as polygons corresponding to the

174 areas where they are present only during the breeding season) were analysed separately from

175 non-breeding distributions (defined as polygons where they are present only during the non-

176 breeding season). We focused solely on land birds, as the geographical distribution of marine

177 species is not well known and represents less than $3 \%$ of avian species.

We statistically examined our data for an association between habitat and plumage

patterns for each biological combination. For adult breeding and non-breeding plumages, we used the breeding and non-breeding geographical distributions of bird species, respectively. For juvenile plumages, we used the breeding geographical distributions as this life stage occurs

182 predominantly during the adult breeding season. Note that for resident species (i.e. non-migrants; $85 \%$ of avian species), the breeding and non-breeding geographical distributions are the same. Irregular patterning is found in $24 \%$ of the 8006 avian species analysed (1887 species) whereas regular patterning is found in $23 \%$ (1858 species). Of the regular patterns (scaled, barred and spotted), scaled and spotted patterns are prevalent in 25\% (470 species) and 30\% (549 species) of avian species (across biological combinations) respectively, whereas barring is observed in 66\% (1220 species) of avian species (across biological combinations) - percentages are relative to the number of species with regular plumage patterns in at least one biological combination. we categorized regular patterns in two ways for our analyses: 1) all regular patterns grouped

192 together as a single category, and 2) just barred plumage patterns due to these being the most 193 frequent type of regular pattern occurring in bird plumage patterns (Gluckman \& Cardoso, 2009;

194 2010). The results were qualitatively the same for the analyses of regular patterns together and 195 barred plumage patterns alone, and we present the results for the category of all regular patterns 
196 together (a comparison of mottled versus barred patterns for all analyses are available in the 197 supplementary material).

To examine the habitat in which species live, we analysed the habitat types found within

201

202

203

204

205

206

207

208

209

210

211

212

213

214

215

216

217

their geographical distributions. For each species with irregular or regular plumage patterns, we quantified how open or closed is the habitat in which they live, a measure herein called habitat coverage. Information on habitat was obtained from the global MODIS land cover dataset (Channan et al., 2014). We coded forests pixels as closed habitat with a value of 1; savannas, grasslands, wetlands, croplands, snow and ice and barren or sparsely vegetated pixels as open habitat with a value of 0 ; and shrublands, woody savannas and cropland/natural vegetation mosaic pixels as partially closed habitat with a value of 0.5 . For each species, we then quantified habitat coverage as the average habitat value across the pixels found within the species' geographical distribution. This allowed us to obtain a continuous measure of habitat for each species during both its breeding and non-breeding seasons - which can be very different for migrants, representing $\sim 16 \%$ of avian species (Somveille et al., 2013). We then removed species for which no habitat information were available and no plumage patterns were present.

Plumage patterns may be phylogenetically conserved, resulting in similar plumage patterns occurring in closely related species due to phylogenetic inertia (Felsenstein, 1985; Revell et al., 2008) rather than caused by habitats selection. In addition, the tendency of species to resemble related species more so than randomly selected species from a tree breaks the assumption of independence of ordinary least square models (Revell 2010). We therefore 
218 examined the association between plumage patterns and habitat by performing comparative 219 analyses that take phylogenetic relatedness into account.

For each biological combination, we computed a phylogenetic logistic regression model

221 (Ives \& Garland, 2010) with plumage pattern type (regular vs irregular; regular pattern $=0$ and

222 irregular pattern $=1$ ) as the dependent variable and habitat coverage as the explanatory variable

223 (R code: phyloglm(plumage pattern type $\sim$ habitat coverage, phy=tree,

224 method="logistic_IG10")). For each biological combination, the analysis was performed only

225 using species with plumage patterns (regular or irregular). As no phylogenetic signal was

226 detected in the models, we also employed standard generalized linear models (GLMs) for

227 comparison (R code: glm(plumage pattern type $\sim$ habitat coverage, family="binomial")). At

228 large sample sizes, trivially small effects can be detected. Therefore, to examine the statistical

229 significance of the relationship for the GLMs, we evaluated this significance by assessing the 230 goodness-of-fit using the McFadden's pseudo-R² (McFadden 1974). All statistical analyses were

231 performed in R (R Development Core Team 2012); phylogenetic logistic regressions were 232 performed using the phylolm $\mathrm{R}$ package.

Phylogenetic information for bird species was obtained from BirdTree.org (Jetz et al. genera. To account for phylogenetic uncertainties, we performed our statistical analyses (i.e. phylogenetic logistic regression models) on 100 randomly selected trees and reported the observed variation in the parameter estimates. Branch lengths were computed using the Grafen method (Grafen 1989; R function: compute.brlen). In phylogenetic logistic regressions, $a$ captures the phylogenetic signal in the data and can vary between -4 (no phylogenetic signal) and 


\section{Eco-region avian assemblage analysis}

To investigate whether species with regular and irregular plumage patterns were

244 distributed randomly across the world, we examined avian assemblages at the scale of the eco-

245 region (Olson et al., 2001), using a global map of the world's terrestrial eco-regions made

246 available by The Nature Conservancy (2009) (Fig. S1B). The physical component that defines

247 habitat type are the individual units of land (eco-regions) containing habitat type specific plant

248 communities and species, nested within biomes (Olson et al., 2001). We categorized habitat into

249 two main types: closed and open. Closed habitat was defined as broadleaf and coniferous forests

250 as well as Mediterranean forests and the Taiga; and open habitat comprised the various types of

251 grasslands, deserts and tundra as well as the scarce habitats of Inland water, Rock and ice.

252 Mangrove habitat was not considered in our analysis, as it is not clearly composed of solely

253 closed or open habitat.

A bird species was classed as occurring in a given eco-region if its mapped range overlapped with any part of the eco-region. Although this is a coarse species geographical distribution, it represents a good approximation of occurrence given the spatial resolution of the eco-regions (Hurlbert \& Jetz, 2007). Species richness was measured as the number of species occurring in a given eco-region. After removing eco-regions in which no bird species occur, 791 eco-regions remained, of which 293 (37\%) were composed of open habitat and $498(63 \%)$ of closed habitat.

To examine whether the composition of plumage patterns in avian assemblages across the

262 world's eco-regions was random or affected by habitat type, we quantified the ratio of regular to 
263 irregular patterns in each eco-region and compared it to a null expectation based on random

264 distribution of the species. The ratio was calculated as the number of species with regular

265 patterns divided by the number of species with irregular patterns (herein referred to as ratio

266 regular-irregular). For the analysis comparing barred and mottled patterns, the ratio was

267 calculated as the number of barred species divided by the number of mottled species (results are

268 presented in Supplementary Material). To avoid a skew in the distribution, we log transformed

269 this ratio for all of the analyses. Eco-regions without any species with an irregular plumage

270 pattern (2.6\% of the eco-regions on average across the biological combinations) were excluded

271 from this analysis because the ratio could not be calculated.

The null distribution of plumage pattern ratios across the world's eco-regions was

274 pool (i.e. treating Western and Eastern Hemispheres separately). In each eco-region, we drew a

275 number of species corresponding to the observed species richness of the local assemblage, and

276 identified eco-regions with significantly high or low values to the null expectation.

To take spatial autocorrelation into account - whereby species occurring in the local pool of species (i.e. in the neighbouring eco-regions) are more likely to occur in the focal eco-regionwe weighted the probability of sampling species based on their degree of occurrence in the local pool. In each avian assemblage (i.e. eco-region), for each species in the hemispherical pool, we determined the proportion of neighbouring eco-regions in which it occurs. Then, for each

282 discrete proportion (i.e. because each eco-region has a discrete number of direct neighbours), we calculated the proportion of species occurring in the focal eco-region. For example, for a given

284 focal eco-region, among all of the species occurring in $50 \%$ of the adjoining neighbours, $30 \%$ of 
286 function in R) to estimate the parameters of this relationship across all the eco-regions (treating

287 the western and eastern hemispheres separately). The fitted curve was then used to determine the 288 probability of a species to occur in a focal eco-region given its occurrence in the neighbouring 289 eco-regions (i.e. the local pool).

290 We examined the species of the Western hemisphere (the Americas; defined as longitude $291<-30^{\circ} \mathrm{W}$ ) separately from the Eastern hemisphere (the Old World; defined as longitude $>-30^{\circ}$

292 W) as they have distinctive avian species pools. For example, the total ratio regular-irregular 293 (as well as the total ratio barred-mottled) is different between these two hemispheres (see 294 supplementary Table S2 and Fig. S3). The global species pool from which species were drawn 295 was therefore separated into two species pools representing each hemisphere.

Following the camouflage hypothesis, we expect the ratio regular-irregular to be higher 297 in open habitats than the expected null values (e.g. regular patterns dominate), and to be smaller 298 than the null expectation in closed habitats (e.g. irregular patterns dominate). To test this 299 hypothesis, we computed a p-value by comparing the observed value to the distribution of null 300 values. If the eco-region was composed of open habitat, we used 1 minus the cumulative 301 probability because we expect the ratio regular-irregular to be higher than the null expectation.

302 To account for multiple testing (i.e. one test for each eco-region) we controlled the false

303 discovery rate using the method developed by Benjamini and Hochberg (1995). 


\section{Results}

306

307

308

309

310

311

312

313

314

315

316

317

318

319

320

321

322

323

324

325

326

All types of plumage patterns are found in all biological combinations of females, males and juveniles, for non-breeding and breeding plumage on both the ventral and dorsal surface (Table S1). Mottled plumage is the most prevalent plumage pattern and is found on the dorsal surface more frequently than on the ventral surface in all sex/age classes, and is least frequent in males. Barred patterns are also common and are frequently found on the ventral surface of breeding adult males, but also in juveniles. Scaled and spotted patterns are less prevalent and are frequently biased towards the dorsal surface of adults and the ventral surface of juveniles. However, spotted patterns are also frequently found on the ventral surface of breeding males and females.

\section{Phylogenetic comparative analysis}

Figure 2 shows very little difference in habitat coverage between species with regular versus irregular plumage patterns for all biological combinations, which was confirmed by the statistical models (Table 1). Phylogenetic uncertainty due to randomly resolving species with missing data by assuming monophyletic genera did not meaningfully affect the results (Table 1). For all biological combinations of plumage patterns, $a$ was very nearly -4 indicating that almost no phylogenetic signal could be detected in the data for plumage patterns. Due to the lack of phylogenetic signal, estimates of intercepts and slopes were almost identical between phylogenetic logistic regressions and GLMs (Table 1). Although most slopes were significantly different from the null hypothesis for both phylogenetic logistic regressions and GLMs, the association between plumage pattern type and habitat coverage using GLMs yielded extremely 
327 low $\mathrm{R}^{2}$ values $(0.001-0.039)$ with a median $\mathrm{R}^{2}$ of 0.0065 (Table 1$)$. In addition to the low

328 explanatory power, all the models showed a negative relationship between plumage patterns and

329 habitat coverage, indicating that regular patterns are more associated with closed environments

330 relatively to irregular patterns that are more associated with open environments, contrary to the

331 camouflage hypothesis.

332

333

Eco-region avian assemblage analysis

334

Across the world's eco-regions, and age, sex and breeding combinations, avian

335

336

337

338

340

341

342

343

344

345

346

347

assemblages had similar proportions of species with regular and irregular plumage patterns, regardless of habitat type (Fig. 3; supplementary Fig. S2). In addition, all eco-regions contained qualitatively the same ratio of species with and without plumage patterns for each biological combination, regardless of habitat type (Fig. 3; supplementary Fig. S3).

The observed ratio regular-irregular in the eco-regions of both open and closed habitats rarely differed from the null expectation (Table 2; similar results were obtained for the ratio barred-mottled; supplementary Table S4). Less than 1\% of eco-regions with species of birds with patterns had a ratio regular-irregular significantly lower than the null expectation for any biological combination (Table. 2), and most of these eco-regions were located on islands.

\section{Discussion}

All types of plumage patterns have evolved in juveniles, females and males in nonbreeding and breeding plumage, on both the ventral and dorsal surface (Table S1), and species 
348 with regular plumage patterns did not differ on average in the type of habitat in which they occur

349 from species with irregular plumage patterns (Table 1; Fig. 2). In fact, contrary to prevailing

350 sensory ecology based hypotheses of the function of patterns in camouflage, we did not find

351 convincing evidence of an association between habitat type and bird plumage patterns at the

352 global spatial and taxonomic scale (Table 1; supplementary Table S2). In addition, we found that

353 species with regular and irregular plumage patterns are distributed at random across the world's

354 eco-regions with respect to one another without any significant effect of the eco-regions' habitat

355 type.

Irregular patterns, which tend to function in stationary camouflage, are unexpectedly

357 found in similar proportion in both closed as well as open habitats that have uniform

358 backgrounds (e.g. deserts) where irregular patterns would probably be easier to detect (e.g.

359 Bradbury \& Vehrencamp, 1998; Dimitrova \& Merilaita, 2009; Hall et al., 2013). Contrary to our

360 predictions, regular patterns are also found in similar proportion in more visually noisy closed

361 habitats where limited space and obstructed transmission would make it difficult to invoke their

362 function in motion dazzle/flicker-fusion camouflage (e.g. Brodie, 1989; 1992; 1993; Lindell \&

363 Forsman, 1996; Stevens et al., 2008; Scott-Samuel et al., 2011; Helversen et al., 2013; How \&

364 Zanker, 2014).

365 The finding that habitat had no effect on the presence of regular patterns on the ventral

366 (breeding) surface of males (in particular barred patterns; Gluckman \& Cardoso, 2010) would be

367 expected under sexual selection, if regular patterns function solely to maximise conspicuousness

368 to conspecifics. However, visual signals should diverge in biological hotspots due to species

369 recognition/sexual selection (Bradbury \& Vehrencamp, 1998). Habitat may influence whether

370 the pattern stands out against its background, for example by being conspicuous against a 
371 uniform background or opposing the geometric pattern of the background. Indeed, signalling

372 traits can be correlated with ecological characteristics to drive signal divergence, such as in

373 African cichlid fish and Anolis lizards (Leal \& Fleishman, 2004; Seehausen et al., 2008) as well

374 as in birds (Doutrelant et al., 2016). Other factors, such as whether the pattern is able to convey

375 aspects of individual quality, would influence their evolution independent of the viewing

376 background. This perhaps may explain why barred patterns have repeatedly evolved

377 independently on the ventral surface of males (Gluckman \& Cardoso, 2010). Conceivably, the

378 same forces of sexual selection/species recognition may have shaped the evolution of the other

379 types of patterns in males, such as spotted patterns (Roulin et al., 2000; b; Petrie \& Halliday,

380 2008; Muck \& Goymann, 2011; Pérez-Rodríguez et al., 2013).

plumage patterns from deserts to tropical forests. First, it could be due to the coarse scale at

which we investigated the association between habitat and plumage patterns. Many of the

empirical studies that demonstrate a camouflage function of patterns in non-colour changing

et al., 2014; Marshall et al., 2015b; Wilson-Aggarwal et al., 2016) or were found via predator-

prey computer simulations (e,g, Stevens et al., 2008, 2011; Scott-Samuel et al., 2011; Troscianko

et al., 2013; How and Zanker, 2014; Hughes et al., 2014; reviewed in Marshall and Gluckman,

2015). At the level of microhabitats, some studies demonstrate that individual behaviours may

facilitate camouflage, such as a behavioural choice to rest on backgrounds that enhance

camouflage (Tsurui et al. 2010; Lovell et al. 2013; Kang et al. 2014; Marshall et al. 2015b;

Troscianko et al., 2016 ; Wilson-Aggarwal et al., 2016). Under current camouflage theory, 
394 associated with all habitats, as it is typically invoked in static camouflage. However, as regular

395 patterns in camouflage are activated by motion, they would very likely need to be associated with

396 only open habitats. Yet, no association was found at the scale we investigated and both irregular

397 and regular patterns were randomly distributed and showed no difference in their geographic

398 distribution with uniformly coloured avian species and no difference between any biological

399 combination (Figs. 2 and 3; Table 1).

In addition, the visual sensitivities of potential observers can alter the visual affect of patterns in different environments, which we did not consider here. For example, in reef fish, regular patterns become blurred at a distance and match the background to prevent detection by fish predators (Marshall, 2000), and certain patterns are imperceptible to some visual systems and may be highly visible to others in certain environments (e.g. Cummings et al., 2003; Siebeck et al., 2010). Thus, avian camouflage patterns may be tuned to deceive predators' visual systems in certain environments by distance-dependent effects and by exhibiting signals that predator visual systems cannot detect (private communication channels). However, to create a distancedependent effect, regular patterns would require space to blur the pattern and should therefore have been associated with more open habitats, especially on the dorsal surface of females and juveniles, which was not what we found.

412 may present different visual microhabitat backgrounds that alter the selection for pattern type.

413 The tops of trees are more open and may allow for more movement required for motion-

414 dazzle/flicker-fusion regular patterns whereas ground-dwelling species may benefit from

415 background matching irregular patterning. Similarly, open habitat such as savannahs and 416 grasslands contain patches of closed environment such as bushes and isolated trees in which 
417 static camouflage via irregular plumage patterning might be favoured. Moreover, more closed

418 habitats will be darker due to shade, and predator risk might be lower due to reduced visual

419 perception and increased clutter, so perhaps camouflage in highly cluttered environments is less

420 likely to be favoured by selection. Conversely, in open environments, both regular and irregular

421 patterns are likely to be found for dual functions in camouflage and communication.

422

Developmental constraint may also explain repeated convergence of the four types of

423 plumage patterns independent of function. For example, white patches of plumage can be

424 attributed to morphogen production (Price and Pavelka 1996) and body size may be negatively

425 related to plumage colour heterogeneity in birds (Galvan et al 2013). Riegner (2008) was the first

426 to study the recurrence of plumage pattern elements across the class Aves and emphasised

427 developmental constraint as a mechanism of parallelism rather than convergence. However,

428 patches of pigmentation over the body (e.g. counter shading) were the major focus of this study,

429 and so scales were not included and spots were largely grouped with drab/blended plumage. The

430 results of Riegner's study demonstrated that some plumage patterns shift along a trajectory

431 correlated with body size and that neither habitat nor common descent adequately predicted the

432 evolution of patches of bold pigmentation over the body in aquatic or marine habitats. Also,

433 striped (mottled) patterns appeared to be more frequent in Passerines whereas bars are more

434 prevalent in large bodied species, e.g. Galliformes, raptors, etc. However, Riegner's (2008)

435 analysis did not control for phylogeny. Based on a theoretical model of reaction-diffusion based

436 plumage pattern formation (Prum \& Williamson, 2002), the evolutionary trajectory of plumage

437 in Anseriformes and Galliformes followed the same pathways within and between patches of

438 plumage over the body (Gluckman and Mundy, 2016). Given that Anseriformes and Galliformes

439 are diverse in life history attributes, this result warrants further investigation at the 
440

441

442

443

444

445

446

447

448

449

450

451

452

453

454

455

456

457

458

459

460

macroevolutionary scale. Nevertheless, these studies indicate that there may be developmental constraint in plumage pattern evolution that may have implications for natural selection.

Few patterns may be enough to reduce predation by increasing the number of predator search images, which may also favour polymorphisms within species. For example, there is frequency-dependent selection on alternative morphs of Tetrix subulata grasshoppers, where each morph has varying amounts of mottled patterns in varying colours. However, when all morphs are present in a population, all morphs benefit by providing variation in the search image of predators (Karpestam et al., 2014). In the case of birds, perhaps the four different types of patterns, in the context of a community of avian species that may also comprise uniform coloration without patterns, may benefit all member species. Although intraspecific polymorphism is quite different to interspecific variation, intraspecific polymorphism via adaptation to different habitats may be the first step to speciation leading to interspecific variation (reviewed in Boughman, 2002; Stevens, 2013; McLean \& Stuart Fox, 2014).

In summary, we found no convincing evidence for an association between habitat type and plumage pattern in land birds worldwide, and the distribution of plumage patterns across the world appears to be random rather than affected by habitat type. These results opposes the hypothesis that closed habitat should contain more species with irregular plumage pattern and open habitat more species with regular plumage pattern, as a result of habitat selection for camouflage. This is an intriguing result that implies that plumage pattern evolution does not conform to the prevailing views of selection for camouflage at the global spatial and taxonomic scale. 


\section{Acknowledgements}

463 We would like to thank Trevor Price and two anonymous reviewers for insightful

464 comments as well as John A Endler, Nicholas I Mundy, Fabien Laroche and Andrea Manica for

465 thoughtful feedback as well as Dieter Lukas for technical advice on comparative approaches.

466

467 


\section{References}

469 Arlott, N. 2007. Birds of Europe, Russia, China, and Japan, Passerines. Princeton: Princeton $470 \quad$ University Press.

471 Arlott, N. 2009. Birds of Europe, Russia, China and Japan, Non- Passerines. Princeton:

$472 \quad$ Princeton University Press.

473 Beehler BM, Pratt TK \& Zimmerman DA. 1986. Birds of New Guinea. Princeton: Princeton $474 \quad$ University Press.

475 Benjamini Y \& Hochberg Y. 1995. Controlling the false discovery rate: a practical and powerful 476 approach to multiple testing. Journal of the Royal Statistical Society B 57: 289-300.

477 Birdlife International \& NatureServe. 2012. Bird species distribution maps of the world. 478 Cambridge: BirdLife International \& Arlington: NatureServe. Available at: http://www.birdlife.org/datazone/info/spcdownload (accessed 4th July 2013)

480

481

482 483

Brazil M. 2009. Birds of East Asia, China, Taiwan, Korea, Japan, and Russia. Princeton: Princeton University Press.

Boughman JW. 2002. How sensory drive can promote speciation. Trends in Ecology and Evolution 17(12): 571-577.

Bradbury JW \& Vehrencamp SL. 1998. Principles of Animal Communication. Sunderland: Sinauer Associates.

Brodie ED. 1993. Consistency of individual differences in anti-predator behaviour and colour pattern in the garter snake, Thamnophis ordinoides. Animal behaviour 45: 851-861. 
488 Brodie ED. 1992. Correlational Selection for Color Pattern and Antipredator Behavior in the 489 Garter Snake Thamnophis ordinoides. Evolution 46: 1284-1298.

490

491

492

493

494

495

496

497

498

499

500

501

502

503

504

505

506

Brodie ED. 1989. Genetic correlations between morphology and antipredator behaviour in natural populations of the garter snake Thamnophis ordinoides. Nature 342: 542-543.

Channan S, Collins K \& Emanuel WR. 2014. Global mosaics of the standard MODIS land cover type data. University of Maryland and the Pacific Northwest National Laboratory, College Park, Maryland, USA. http://glcf.umd.edu/data/lc/, accessed 01/10/2015.

Coates BJ \& Bishop DK. 1997. A Guide to the Birds of Wallacea. Alderley: Dove Publications.

Cott HB. 1940. Adaptive Coloration in Animals. Oxford: Oxford University Press.

Cummings ME, Rosenthal GG \& Ryan MJ. 2003. A private ultraviolet channel in visual communication. Proceedings of the Royal Society B: Biological Sciences. 270: 897-904.

Dale J, Dey CJ, Delhey K, Kempenaers B \& Valcu M. 2015. The effect of life history and sexual selection on male and female plumage colouration. Nature 527: 367-370.

De La Pena MR \& Rumboll M. 1998. Birds of Southern South America and Antarctica. Princeton: Princeton University Press.

Dimitrova M \& Merilaita S. 2009. Prey concealment: visual background complexity and prey contrast distribution. Behavioral Ecology 21: 176-181.

Doutrelant C, Paquet M, Renoult JP, Grégoire A, Crochet P-A \& Covas R. 2016. Worldwide patterns of bird colouration on islands. Ecology Letters 19(5): 537-545. 
507 Dunn PO, Armenta JK \& Whittingham LA. 2015. Natural and sexual selection act on different

$508 \quad$ axes of variation in avian plumage color. Science Advances 1: e1400155.

509 Endler JA. 1978. Evolutionary Biology (M. K. Hecht, W. C. Steere, \& B. Wallace, eds). Boston:

$510 \quad$ Springer US.

511 Endler JA. 1992. Signals, Signal Conditions, and the Direction of Evolution. American

$512 \quad$ Naturalist 139: 125-153.

513 Felsenstein J. 1985. Phylogenies and the Comparative Method. American Naturalist 125: 1-15.

514 Galvan I, Negro JJ, Rodriguez A \& Carrascal LM. 2013. On showy dwarfs and sober giants:

515 body size as a constraint for the evolution of bird plumage colouration. Acta Ornithologica 48:

$516 \quad 65-80$.

517 Garcia JE, Rohr D \& Dyer AG. 2013. Trade-off between camouflage and sexual dimorphism

518 revealed by UV digital imaging: the case of Australian Mallee dragons (Ctenophorus fordi).

519 Journal of Experimental Biology. 216: 4290-4298.

520 Gluckman T-L \& Cardoso GC. 2009. A Method to Quantify the Regularity of Barred Plumage

521 Patterns. Behavioral Ecology and Sociobiology 63: 1837-1844.

522 Gluckman T-L \& Cardoso GC. 2010. The dual function of barred plumage in birds: camouflage

523 and communication. Journal of Evolutionary Biology 23: 2501-2506.

524 Gluckman T-L \& Mundy NI. 2016. Evolutionary pathways to convergence in plumage patterns.

$525 \quad$ BMC Evolutionary Biology 16: 172.

526 Gluckman T-L 2014. Pathways to elaboration of sexual dimorphism in bird plumage patterns. 
528 Grafen A. 1989. The phylogenetic regression. Philosophical Transactions of the Royal society of 529 London. Series B. Biological Sciences 326: 119-157.

530 Grimmett R, Inskipp C \& Inskipp T. 1999. Birds of India, Pakistan, Nepal, Bangladesh, Bhutan, 531 Sri Lanka and the Maldives. Princeton: Princeton University Press.

532 Hall JR, Cuthill IC, Baddeley R, Shohet AJ \& Scott-Samuel NE. 2013. Camouflage, detection 533 and identification of moving targets. Proceedings of the Royal Society B: Biological $534 \quad$ Sciences 280: 1758.

535 Heinzel H, Fitter R \& Parslow J. 1995. Birds of Britain \& Europe. London: Harper Collins $536 \quad$ Publishers.

537

538

544 How MJ \& Zanker JM. 2014. Motion camouflage induced by zebra stripes. Zoology 117: 163545

Helversen vonB, Schooler LJ \& Czienskowski U. 2013. Are Stripes Beneficial? Dazzle Camouflage Influences Perceived Speed and Hit Rates. PLoS ONE 8: e61173.

Hoekstra HE, Hirschmann RJ, Bundey RA, Insel PA \& Crossland JP. 2006. A single amino acid mutation contributes to adaptive beach mouse color pattern. Science 313: 101-104.

Hoekstra HE, Krenz JG \& Nashman NW. 2005. Local adaptation in the rock pocket mouse (Chaetodipus intermedius): natural selection and phylogenetic history of populations. Heredity 94: 217-228 170.

Hughes AE, Troscianko J \& Stevens M. 2014. Motion dazzle and the effects of target patterning 
on capture success. BMC Evolutionary Biology 14: 201-201.

548 Hurlbert AH \& Jetz W. 2007. Species richness, hotspots, and the scale dependence of range

549 maps in ecology and conservation. Proceedings of the National Academy of Sciences of the

$550 \quad$ United States of America 104: 13384-13389.

551 Ives AR \& Garland T Jr 2010. Phylogenetic logistic regression for binary dependent variables.

$552 \quad$ Systematic Biology 59: 9-26.

553 Jetz W, Thomas GH, Joy JB, Hartmann K \& Mooers AO. 2012. The global diversity of birds in $554 \quad$ space and time. Nature 491: 444-448.

555 Kang C, Stevens M, Moon J, Lee S \& Jablonski PG. 2014. Camouflage through behavior in 556 moths: the role of background matching and disruptive coloration. Behavioral Ecology 26: $557 \quad 45-54$.

558 Karpestam E, Merilaita S \& Forsman A. 2014. Natural levels of colour polymorphism reduce 559 performance of visual predators searching for camouflaged prey. Biological Journal of the $560 \quad$ Linnean Society 112(3): 546-555.

561 Kenward B, Wachtmeister C-A, Ghirlanda S \& Enquist M. 2004. Spots and stripes: the evolution 562 of repetition in visual signal form. Journal of Theoretical Biology 230: 407-419.

563 Langrand O. 1990. A Guide to the Birds of Madagascar. New Haven: Yale University Press.

564 Leal M \& Fleishman LJ. 2004. Differences in visual signal design and detectability between 565 allopatric populations of Anolis lizards. American Naturalist 163: 26-39.

566 Lindell LE \& Forsman A. 1996. Density effects and snake predation: prey limitation and reduced 
567

568

569

570

571

572

573

574

575

576

577

578

579

580

581

582

583

584

585

586

growth rate of adders at high density of conspecifics. Canadian Journal of Zoology 74:

$1000-1007$.

Lovell PG, Ruxton GD, Langridge KV \& Spencer KA. 2013. Egg-laying substrate selection for optimal camouflage by quail. Current Biology 23(3): 260-264.

MacKinnon J \& Phillips K. 1993. A field guide to the birds of Borneo, Sumatra, Java and Bali (The greater Sunda islands). New York: Oxford University Press.

Marshall JN. 2000. Communication and Camouflage with the Same "Bright" Colours in Reef Fishes. Philosophical Transactions of the Royal society of London. Series B. Biological Sciences 355: 1243-1248.

Marshall KLA \& Gluckman T-L. 2015. The evolution of pattern camouflage strategies in waterfowl and game birds. Ecology and Evolution 5(10):1981-1991.

Marshall KLA, Philpot KE, Damas-Moreira I \& Stevens M. 2015a. Conspicuous male coloration impairs survival against avian predators in Aegean wall lizards, Podarcis erhardii. Ecology and Evolution 5(18): 4115-4131.

Marshall KLA, Philpot KE \& Stevens M. 2015b. Intraspecific colour variation among lizards in distinct island environments enhances local camouflage. PLoS ONE 10: e0135241.

McFadden D. 1974. Conditional logit analysis of qualitative choice behavior. In: Zarembka P, ed. Frontiers in Econometrics. New York: Academic Press, 105-142

McLean CA \& Stuart Fox D. 2014. Geographic variation in animal colour polymorphisms and its role in speciation. Biological Reviews 89: 860-873. 
587 McLean CA, Moussalli A \& Stuart-Fox D. 2014. Local adaptation and divergence in colour

588 signal conspicuousness between monomorphic and polymorphic lineages in a lizard. Journal 589 of Evolutionary Biology 27: 2654-2664.

590 Muck C \& Goymann W. 2011. Throat patch size and darkness covaries with testosterone in 591 females of a sex-role reversed species. Behavioral Ecology 22: 1312-1319.

592 The Nature Conservancy. 2009. Terrestrial Ecoregions of the World. Arlington: The Nature 593 Conservancy. Available at: http://maps.tnc.org/gis_data.html (Accessed April 24 ${ }^{\text {th }}$ 2015).

594 Olson DM, Dinerstein E, Wikramanayake ED, Burgess ND, Powell GVN, Underwood EC, 595 D'amico JA, Itoua I, Strand HE, Morrison JC, Loucks CJ, Allnutt TF, Ricketts TH, Kura Y, Lamoreux JF, Wettengel WW, Hedao P \& Kassem KR. 2001. Terrestrial Ecoregions of the

Petrie M \& Halliday T. 2008. Experimental and natural changes in the peacocks (Pavo cristatus)

600 train can affect mating success. Behavioral Ecology and Sociobiology 35: 213-217.

601

602

603 604 605 606
Pérez-Rodríguez L, Jovani R \& Mougeot F. 2013. Fractal geometry of a complex plumage trait reveals bird's quality. Proceedings of the Royal Society B: Biological Sciences 280.

van Perlo B. 2006. Birds of Mexico and Central America. Princeton: Princeton University Press.

Pratt HD, Bruner PL \& Berrett DG. 1987. The Birds of Hawaii and the Tropical Pacific. Princeton: Princeton University Press.

Pough FH. 1976. Multiple Cryptic Effects of Crossbanded and Ringed Patterns of Snakes. 

Copeia 1976: 834-836.

608 Price T \& Pavelka M. 1996. Evolution of a colour pattern: history, development and selection. 609 Journal of Evolutionary Biology 9: 451-470.

610 Prum RO \& Williamson S. 2002. Reaction-diffusion models of within-feather pigmentation 611 patterning. Proceedings of the Royal Society B: Biological Sciences 269: 781-792.

612 R Development Core Team. 2012. R: A Language and Environment for Statistical Computing. 613 Vienna: R Foundation for Statistical Computing. http://www.R-project.org.

614 Restall R, Rodner C \& Lentino M. 2007. Birds of Northern South America. New Haven: Yale $615 \quad$ University Press.

616 Revell LJ. 2010. Phylogenetic signal and linear regression on species data. Methods in Ecology 617 and Evolution 1:319-329.

618 Revell LJ, Harmon LJ \& Collar DC. 2008. Phylogenetic signal, evolutionary process, and rate. 619 Systematic Biology 57: 591-601.

Riegner MF. 2008. Parallel evolution of plumage pattern and coloration in birds: implications for 621 defining avian morphospace. Condor 110: 599-614.

622 Robertson H \& Heather B. 2005. The Hand Guide to the Birds of New Zealand. Auckland: 623 Penguin Books.

624 Robson C. 2005. Birds of Southeast Asia. Princeton: Princeton University Press.

625 Rosenblum EB. 2006. Convergent evolution and divergent selection: lizards at the White Sands 
626

627

628

629

630

631

632

633

634

635

636

637

638

639

640

641

642

643

644

ecotone. American Naturalist 167: 1-15.

Roulin A, Jungi TW, Pfister H \& Dijkstra C. 2000. Female barn owls (Tyto alba) advertise good genes. Proceedings of the Royal Society B: Biological Sciences 267: 937-941.

Scott-Samuel NE, Baddeley R, Palmer CE \& Cuthill IC. 2011. Dazzle camouflage affects speed perception. PLOS ONE 6: e20233.

Seehausen O, Terai Y, Magalhaes IS, Carleton KL, Mrosso HDJ, Miyagi R, van der Sluijs I, Schneider MV, Maan ME, Tachida H, Imai H \& Okada N. 2008. Speciation through sensory drive in cichlid fish. Nature 455: 620-626.

Sibley DA. 2000. The Sibley Guide to Birds. New York: Alfred Knopf.

Siebeck UE, Parker AN, Sprenger D, Mäthger LM \& Wallis G. 2010. A species of reef fish that uses ultraviolet patterns for covert face recognition. Current Biology 20: 407-410.

Simpson K \& Day N. 2004. Birds of Australia. 7th edn. Princeton: Princeton University Press.

Sinclair I \& Ryan P. 2003. Birds of Africa south of the Sahara. Johannesburg: Struik Publishers.

Somveille M, Manica A, Butchart SHM \& Rodrigues ASL. 2013. Mapping global diversity patterns for migratory birds. PLoS, 8: e70907.

Stevens M. 2013. Sensory Ecology, Behaviour, and Evolution. Oxford: Oxford University Press.

Stevens M \& Merilaita S. 2009. Defining disruptive coloration and distinguishing its functions. Philosophical Transactions of the Royal society of London. Series B. Biological Sciences 364: $481-488$. 
645 Stevens M, Searle WTL, Seymour JE, Marshall KL \& Ruxton GD. 2011. Motion dazzle and 646 camouflage as distinct anti-predator defenses. BMC Biology 9: 81.

647 Stevens M, Yule DH \& Ruxton GD. 2008. Dazzle coloration and prey movement. Proceedings 648 of the Royal Society B: Biological Sciences 275: 2639-2643.

649 Stuart-Fox DM, Moussalli A, Johnston GR \& Owens IPF. 2004. Evolution of colour variation in 650 dragon lizards: quantitative tests of the role of crypsis and local adaptation. Evolution 58: $651 \quad 1549-1559$.

652 Stuart-Fox DM \& Ord TJ. 2004. Sexual selection, natural selection and the evolution of 653 dimorphic coloration and ornamentation in agamid lizards. Proceedings of the Royal Society 654 B: Biological Sciences 271: 2249-2255.

655

656

657

658

659

660

661

662

663

664

Thayer GH. 1909. Concealing-Coloration in the Animal Kingdom; an Exposition of the Laws of Disguise Through Color and Pattern. London: Macmillan.

Troscianko J, Wilson-Aggarwal J, Stevens M \& Spottiswoode CN. 2016. Camouflage predicts survival in ground-nesting birds. Scientific Reports 6: 19966.

Tsurui K, Honma A \& Nishida T. 2010. Camouflage effects of various colour-marking morphs against different microhabitat backgrounds in a polymorphic pygmy grasshopper Tetrix japonica. PLoS ONE 5(7): e11446.

Vignieri SN, Larson JG \& Hoekstra HE. 2010. The selective advantage of crypsis in mice. Evolution 64: 2153-2158.

Wilson-Aggarwal JK, Troscianko JT, Stevens M \& Spottiswoode CN. 2016. Escape distance in 
665 ground-nesting birds differs with individual level of camouflage. The American Naturalist

$666 \quad$ 188(2): 231-239.

667

668 
669 Table 1. Relationship between plumage pattern type (regular versus irregular) and habitat (using 670 our habitat coverage measure) across the class Aves using Phylogenetic Logistic Regressions

671 (PhyLoRegs) and Generalized Linear Models (GLMs). We present the estimate of the intersect

672 as well as the slope and its associated p-value for both PhyLoRegs and GLMs. For PhyLoRegs,

673 values correspond to the mean of 100 runs using randomly sampled phylogenetic trees from Jetz

674 et al. (2012), and values in brackets correspond to the standard deviation. Positive slopes indicate

675 that regular patterns are more associated with open habitat while irregular patterns are more

676 associated with closed habitat, and negative slopes indicate the opposite. $a$ is the phylogenetic

677 correlation parameter calculated from the PhyLoRegs. $\mathrm{R}^{2}$ values were computed for the GLMs

678 and correspond to the McFadden's pseudo-R ${ }^{2}$. Season: NB = Non-breeding; BR = Breeding.

\begin{tabular}{|c|c|c|c|c|c|c|c|c|c|c|c|}
\hline \multicolumn{3}{|c|}{ Biological combination } & \multirow[b]{2}{*}{$\begin{array}{c}\text { Raw } \\
\text { number } \\
\text { of } \\
\text { species } \\
\end{array}$} & \multicolumn{4}{|c|}{ PhyLoRegs results } & \multicolumn{4}{|c|}{ GLMs results } \\
\hline Sex & $\begin{array}{l}\text { Body } \\
\text { part }\end{array}$ & Season & & Intercept & Slope & P-value & $a$ & Intercept & Slope & P-value & $\begin{array}{l}\text { McFadden' } \\
\text { s pseudo-r2 }\end{array}$ \\
\hline \multirow[t]{2}{*}{ Female } & \multirow[t]{2}{*}{ Ventral } & NB & 1655 & $\begin{array}{c}0.058 \\
\left(<10^{-4}\right)\end{array}$ & $\begin{array}{l}-0.298 \\
\left(<10^{-4}\right)\end{array}$ & $\begin{array}{c}0.001 \\
\left(<10^{-4}\right)\end{array}$ & $\begin{array}{l}-3.993 \\
(0.016)\end{array}$ & 0.058 & -0.298 & 0.067 & 0.001 \\
\hline & & $\mathrm{BR}$ & 1658 & $\begin{array}{c}0.102 \\
\left(<10^{-4}\right)\end{array}$ & $\begin{array}{l}-0.375 \\
\left(<10^{-4}\right)\end{array}$ & $\begin{array}{l}<0.001 \\
\left(<10^{-4}\right)\end{array}$ & $\begin{array}{l}-3.984 \\
(0.026)\end{array}$ & 0.101 & -0.375 & 0.022 & 0.002 \\
\hline \multirow{6}{*}{ Male } & \multirow[t]{2}{*}{ Dorsal } & NB & 1643 & $\begin{array}{c}0.769 \\
\left(<10^{-4}\right)\end{array}$ & $\begin{array}{l}-1.127 \\
\left(<10^{-4}\right)\end{array}$ & $\begin{array}{l}<0.001 \\
\left(<10^{-4}\right)\end{array}$ & $\begin{array}{c}-3.986 \\
(0.018)\end{array}$ & 0.769 & -1.127 & $<0.001$ & 0.021 \\
\hline & & $\mathrm{BR}$ & 1648 & $\begin{array}{c}0.786 \\
\left(<10^{-4}\right)\end{array}$ & $\begin{array}{l}-1.163 \\
\left(<10^{-4}\right)\end{array}$ & $\begin{array}{l}<0.001 \\
\left(<10^{-4}\right)\end{array}$ & $\begin{array}{c}-3.983 \\
(0.026)\end{array}$ & 0.786 & -1.163 & $<0.001$ & 0.022 \\
\hline & \multirow[t]{2}{*}{ Ventral } & NB & 1336 & $\begin{array}{c}0.171 \\
\left(<10^{-4}\right)\end{array}$ & $\begin{array}{l}-0.532 \\
\left(<10^{-4}\right)\end{array}$ & $\begin{array}{l}<0.001 \\
\left(<10^{-4}\right)\end{array}$ & $\begin{array}{l}-3.983 \\
(0.022)\end{array}$ & 0.171 & -0.532 & 0.003 & 0.005 \\
\hline & & $\mathrm{BR}$ & 1334 & $\begin{array}{c}0.147 \\
\left(<10^{-4}\right)\end{array}$ & $\begin{array}{l}-0.575 \\
\left(<10^{-4}\right)\end{array}$ & $\begin{array}{l}<0.001 \\
\left(<10^{-4}\right)\end{array}$ & $\begin{array}{l}-3.973 \\
(0.032)\end{array}$ & 0.147 & -0.575 & 0.002 & 0.005 \\
\hline & \multirow[t]{2}{*}{ Dorsal } & NB & 1502 & $\begin{array}{c}0.843 \\
\left(<10^{-4}\right)\end{array}$ & $\begin{array}{l}-1.457 \\
\left(<10^{-4}\right)\end{array}$ & $\begin{array}{l}<0.001 \\
\left(<10^{-4}\right)\end{array}$ & $\begin{array}{c}-3.993 \\
(0.016)\end{array}$ & 0.843 & -1.457 & $<0.001$ & 0.036 \\
\hline & & $\mathrm{BR}$ & 1478 & $\begin{array}{c}0.901 \\
\left(<10^{-4}\right)\end{array}$ & $\begin{array}{l}-1.553 \\
\left(<10^{-4}\right)\end{array}$ & $\begin{array}{l}<0.001 \\
\left(<10^{-4}\right)\end{array}$ & $\begin{array}{l}-3.989 \\
(0.023)\end{array}$ & 0.901 & -1.553 & $<0.001$ & 0.039 \\
\hline \multirow[t]{2}{*}{ Juvenile } & \multicolumn{2}{|l|}{ Ventral } & 1443 & $\begin{array}{c}0.384 \\
\left(<10^{-4}\right)\end{array}$ & $\begin{array}{l}-0.347 \\
\left(<10^{-4}\right)\end{array}$ & $\begin{array}{l}<0.001 \\
\left(<10^{-4}\right)\end{array}$ & $\begin{array}{l}-3.981 \\
(0.029)\end{array}$ & 0.384 & -0.347 & 0.047 & 0.002 \\
\hline & Dorsal & & 1394 & $\begin{array}{c}0.700 \\
\left(<10^{-4}\right)\end{array}$ & $\begin{array}{l}-0.676 \\
\left(<10^{-4}\right)\end{array}$ & $\begin{array}{l}<0.001 \\
\left(<10^{-4}\right)\end{array}$ & $\begin{array}{l}-3.985 \\
(0.016)\end{array}$ & 0.7 & -0.676 & $<0.001$ & 0.008 \\
\hline
\end{tabular}


679

680 Table 2. Assemblage-level test of an association with habitat type for the ratio regular-irregular.

681 For each biological combination, we present the total number of eco-regions that have avian

682 species with plumage patterns, and the number, proportion and habitat type of eco-regions that

683 have an observed ratio regular-irregular significantly different from the null expectation. Habitat

684 type: $\mathrm{TMBF}=$ Tropical and Subtropical Moist Broadleaf Forests; TDBF $=$ Tropical and

685 Subtropical Dry Broadleaf Forests; MGS = Montane Grasslands and Shrublands; MFWS =

686 Mediterranean Forests, Woodlands and Scrub; FGS = Flooded Grasslands and Savannas; DXS =

687 Deserts and Xeric Shrublands. Season: NB = Non-breeding; BR = Breeding.

688

\begin{tabular}{|c|c|c|c|c|c|c|}
\hline \multicolumn{3}{|c|}{ Biological combination } & \multirow[b]{2}{*}{$\begin{array}{l}\text { Number of } \\
\text { eco-regions }\end{array}$} & \multicolumn{3}{|c|}{ Significant eco-regions } \\
\hline Sex & $\begin{array}{l}\text { Body } \\
\text { part }\end{array}$ & Season & & Number & Proportion & Name \\
\hline \multirow[t]{4}{*}{ Female } & Ventral & NB & 766 & 2 & 0.003 & $\begin{array}{l}\text { Antipodes Subantarctic Islands } \\
\text { Tundra (Tundra - Australasia), } \\
\text { Pantanal (FGS - Neotropics) }\end{array}$ \\
\hline & & $\mathrm{BR}$ & 759 & 0 & 0 & - \\
\hline & Dorsal & NB & 769 & 0 & 0 & - \\
\hline & & $\mathrm{BR}$ & 759 & 1 & 0.001 & $\begin{array}{l}\text { New Caledonia Rain Forests } \\
\text { (TMBF - Australasia) }\end{array}$ \\
\hline \multirow[t]{3}{*}{ Male } & Ventral & NB & 773 & 0 & 0 & - \\
\hline & & $\mathrm{BR}$ & 767 & 2 & 0.003 & $\begin{array}{l}\text { Victoria Basin Forest-Savanna } \\
\text { Mosaic (TMBF - Afrotropics), } \\
\text { Kinabalu Montane Alpine Meadows } \\
\text { (MGS - Indo-Malay) }\end{array}$ \\
\hline & Dorsal & NB & 773 & 2 & 0.003 & $\begin{array}{l}\text { Banda Sea Islands Moist Deciduous } \\
\text { Forests (TMBF - Australasia), New } \\
\text { Britain-New Ireland Montane Rain } \\
\text { Forests (TMBF - Australasia) }\end{array}$ \\
\hline
\end{tabular}


$\begin{array}{llll}\text { BR } & 767 & 6 & 0.008\end{array}$

Juvenile Ventral

Dorsal
763

761
1

2
Admiralty Islands Lowland Rain Forests (TMBF - Australasia), Banda Sea Islands Moist Deciduous Forests (TMBF - Australasia), New Caledonia Dry Forests (TDBF Australasia), Kinabalu Montane Alpine Meadows (MGS - IndoMalay), Fiji Tropical Moist Forests (TMBF - Oceania), Bohai Sea Saline Meadow (FGS - Palearctic)

$0.001 \quad$ Antipodes Subantarctic Islands Tundra (Tundra - Australasia) Zambezian Halophytics (FGS Afrotropics), Kinabalu Montane Alpine Meadows (MGS - IndoMalay)

689

690 
691 Figures

A)

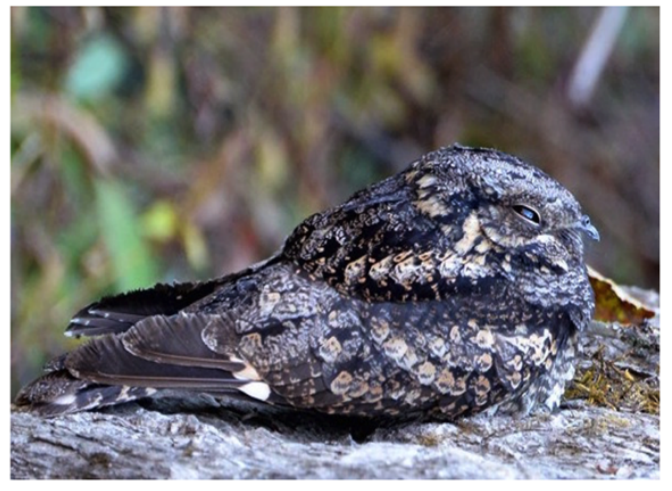

C)

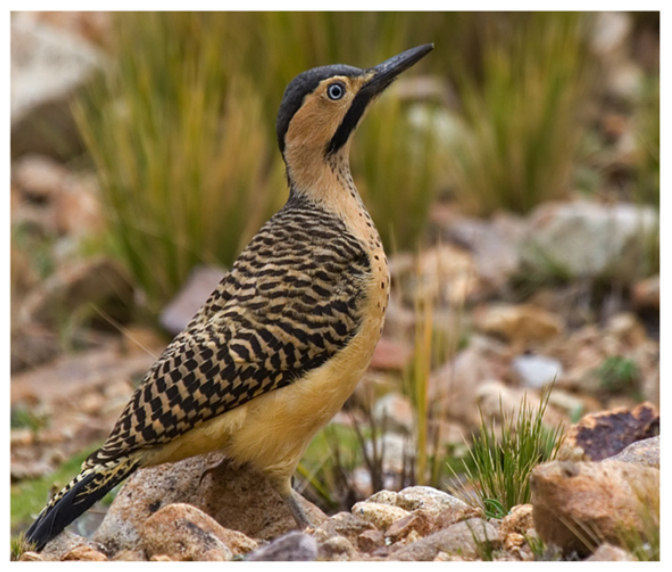

B)

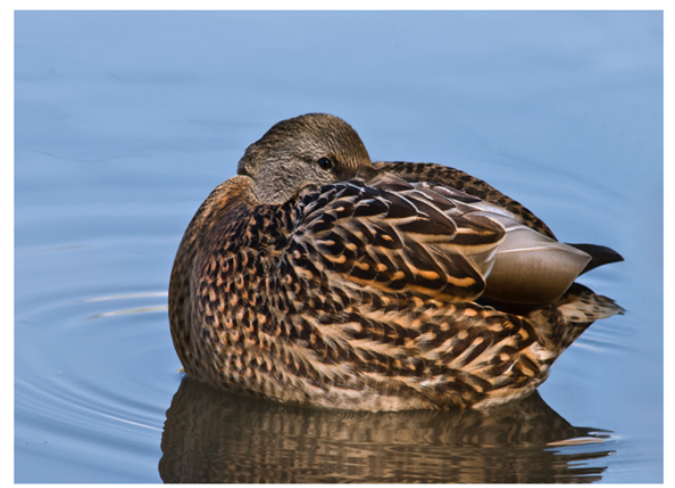

D)

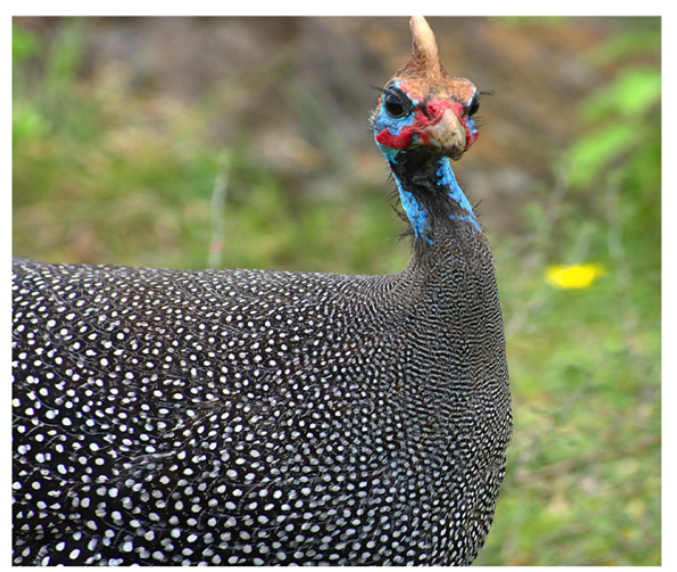

692

693 Figure 1. The predominant types of plumage patterns in birds. A) Irregular mottled plumage

694 consists of feathers that are heterogeneously pigmented (Jungle Nightjar - Caprimulgus indicus

695 indicus). Regular plumage patterns can be comprised of B) scales where pigmentation follows

696 the edge of the vane (Mallard - Anas platyrhynchos), C) bars that are made of alternating dark

697 and light pigmentation transversal to the feathers axis (Andean flicker - Colaptes rupicola), and

698 D) spots where one or more spots pigment each feather (Guineafowl - Numida meleagris).

699 Photos by Koshy Koshy/CC BY 2.0, Alain Carpentier/CC BY-SA 3.0, Adam Kumiszcza/CC

700 BY-SA 3.0 and JP Hamon/CC BY-SA 3.0, respectively. 


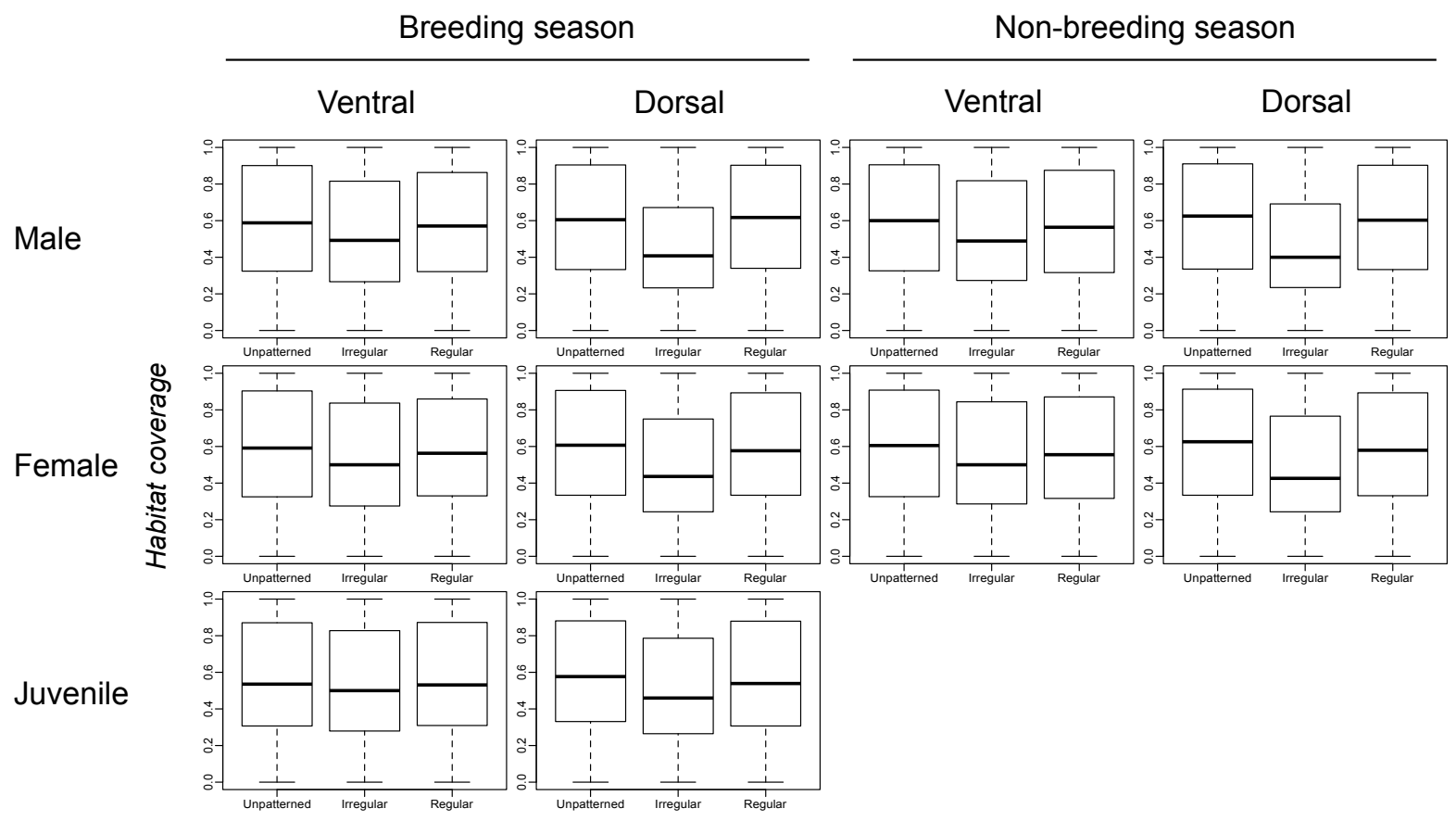

705

706 Figure 2. Comparison of habitat coverage values for species without plumage patterns, species

707 with irregular plumage patterns and species with regular plumage patterns across the class Aves.

708 The comparison was plotted for all biological combinations.

709

710 


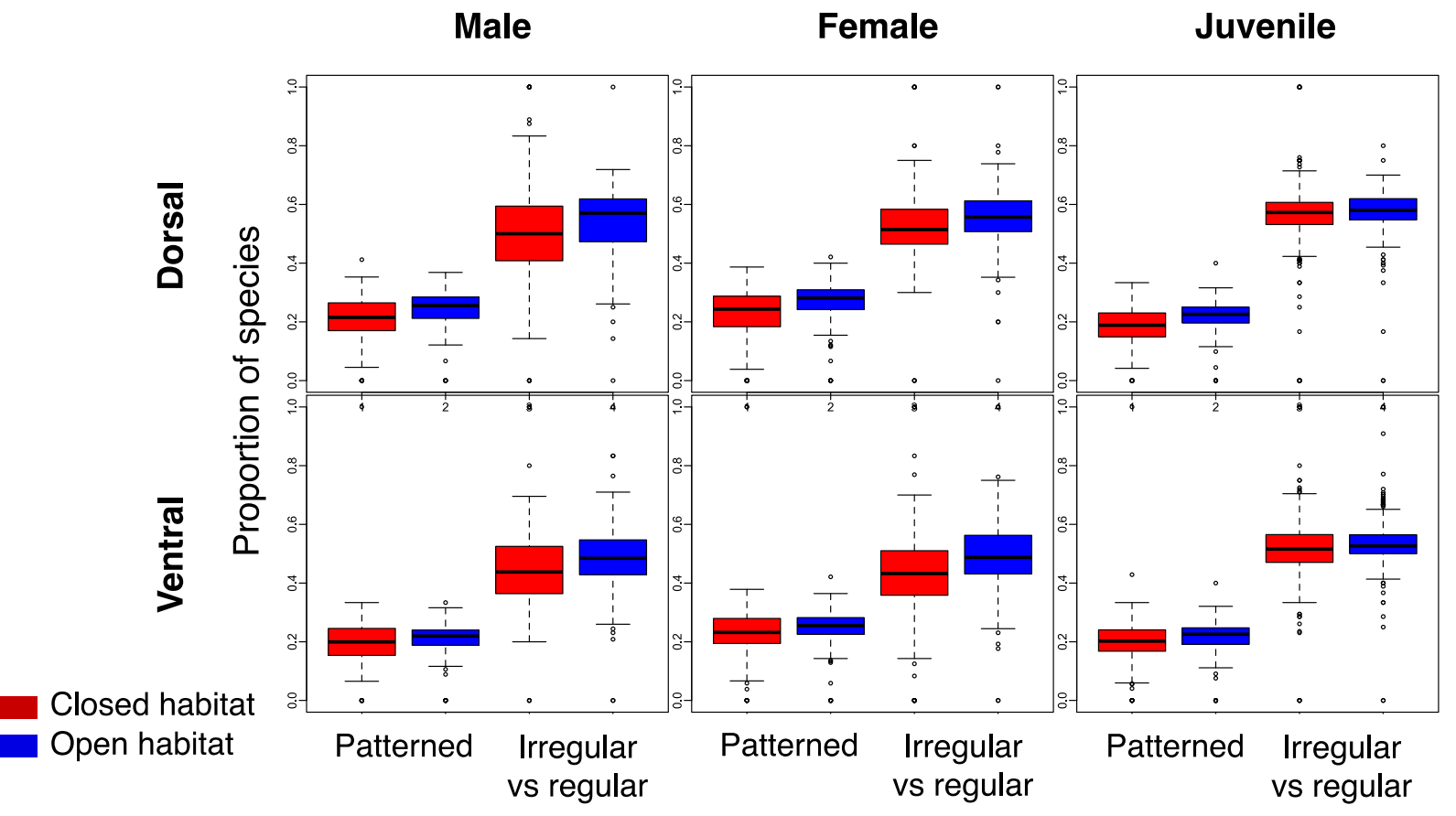

712

713 Fig. 3. Comparison of the proportion of species with plumage patterns versus without, and with

714 irregular versus regular patterns in breeding males and females, as well as juveniles, over the

715 dorsal and ventral surface of land birds. The Patterned boxplots correspond to the proportion of

716 patterned species in eco-regions' avian species assemblages. The Irregular vs regular boxplots

717 correspond to the proportion of irregular versus regular patterns in eco-regions' avian species

718 assemblages for the indicated age/sex class. The boxplots in red correspond to closed habitat and

719 the blue boxplots correspond to open habitat. 